http://jmscr.igmpublication.org/home/ ISSN (e)-2347-176x ISSN (p) 2455-0450

crossref DOI: https://dx.doi.org/10.18535/jmscr/v8i5.02

\author{
Dournal Of Medical Science And Clinical Research \\ IGM Publication \\ An official Publication of IGM Publication
}

\title{
Hematological Malignancies Pattern among Bangladeshi Adults
}

Authors

\section{Lt Col S. M.Rahid Sarwar1, Dr Hafiza Lona ${ }^{2}$, Dr Durba Halder ${ }^{3}$, Dr Shahjada Selim ${ }^{4^{*}}$ \\ ${ }^{1}$ Classified Specialist in Medicine and OJT (medical Oncology) AFMI, Dhaka Cantonment, Dhaka, Bangladesh \\ ${ }^{2}$ Associate Professor, Department of Biochemistry, Medical College for Women's Uttara, Dhaka, Bangladesh \\ ${ }^{3}$ Associate Professor, Department of Medicine Sir Salimullah Medical College\& Mitford Hospital, Dhaka, Bangladesh \\ ${ }^{4}$ Associate Professor, Department of Endocrinology Bangabandhu Sheikh Mujib Medical University, Dhaka,} Bangladesh

*Correspondence Author

Dr Shahjada Selim

\begin{abstract}
Introduction: As a developing country, Bangladesh facing many challenges, especially in the health sector. Among all other crucial diseases, cancer kills more people than tuberculosis, HIV and malaria combined. Hematological malignancies (HM) are not rare in our country. It affects all ages and genders. Hematological malignancies are a group of cancer that arises from a malignant transformation of cells of the bone marrow or lymphatic system. There are several classification systems for hematological malignancies. In a worldwide consensus classification, the World Health Organization (WHO) first classified hematological tumors.

Methods: It was a cross-sectional descriptive study. Data collected from the Department of pathology and hematology unit of internal medicine of Dhaka Medical College Hospital, Bangabandhu Sheikh Mujib Medical University, Combined Military Hospital (CMH) Dhaka, Sir Salimullah Medical College \& Mitford Hospital, National Institute of Cancer Hospital, Chittagong Medical College Hospital and Rajshahi Medical College Hospital from September 2018 to till October 2019. Hematological malignancies were analyzed clinically with laboratory parameters. They were initially analyzed with complete blood counts, peripheral smearand diagnosed on the basis of bone marrow morphological assessment, immunophenotyping, cytogenetic molecular markers, histopathology and immunohistochemistry of excised lymph node when applicable. Plasma cell dyscrasias were assessed clinically for features of CRAB (hypercalcemia, renal impairment, anemia, and lytic lesion) and evaluation was done by hemogram, biochemical parameters, and skeletal survey. Later plasma cell dyscrasias were diagnosed on the basis of bone marrow study, immunofixation electrophoresis, serum-free light chain assay, serum protein electrophoresis and myeloma defining events.
\end{abstract}

Results: A total number of 1100 cases of hematological malignancies (HM) patients were selected in the study. Among them lymphoid neoplasm (LN) was the commonest hematological malignancies which were $60 \%$ and myeloid neoplasm (MN) 40\%. In LN, precuorsor lymphoid were (7.27\%), B and T lymphoblastic lymphoma/ leukemia (ALL) both were 3.6\%. Mature B cell neoplasm (MBCN) was 43.6\%, hodgkin's lymphoma (HL) $5.6 \%$ and mature T cell neoplasm (MTCN) 3.6\%.In myeloid neoplasm (MN), myeloproliferative neoplasm (MPN) accounted for 20.8\% followed by acute myeloid leukemia (AML) with $16.2 \%$ and myelodysplastic syndrome (MDS) $3 \%$. According to the classification of age groups of 21-40 years, non-hodgkinslymphoma (NHL) was the commonest(2.7\%), under MCBN of lymphoid neoplasm. Whereas, chronic myeloid leukemia (CML) was the commonest (5.46\%), among the age group of 41-60 years under MPN of myeloid neoplasm.In older group > 60 years, plasma cell neoplasm (PCN) was the most common (5.5\%).Male was more predominant than female. Male were $23.6 \%$ and female $5.5 \%$ with a ratio $4.3: 1$

Conclusion: HM can occur in any age group. Overall men are more affected with HM than women.In both male and female lymphoid malignancies is frequent HM. There is a difference in distribution patterns and subtypes of hematological malignancies at different age groups.

Keywords: Hematological malignancies; lymphoid neoplasm; myeloid neoplasm. 


\section{Introduction}

In the 1960s, almost $25 \%$ of Global cancer was diagnosed in low-income and lower-middleincome countries. In 2020 nearly 55\% of Global cancer was found in these countries. By 2030, over 13 million people will die from cancer every year. Almost 9 million (about 70\%) of these deaths will be in developing countries ${ }^{1}$. Hematological malignancies (HM) are not uncommon in our country. All ages and genders are affected by HM. Hematological malignancies are a group of cancers that arise from a malignant transformation of cells of the bone marrow or lymphatic system ${ }^{2}$. There are several classification systems for hematological malignancies. In 2001 WHO classification was the first worldwide consensus classification on hematological tumors. The classification is based on information such as clinical, morphologic, biologic, immunophenotypic and genetic features ${ }^{3,4,5,6}$. In 2008, as a part of series of classification of tumors' blue book' monographs (4th edition), published a new classification for hematopoietic and lymphoid neoplasm in collaboration with society for Hematopathology and the European Association for Haematopathology. In 2014, a Clinical Advisory Committee (CAC) proposed revisions to the fourth edition of classification. So, In view of recently identified molecular features, improvisation of morphological features and integrated approach, the fourth edition is being updated in $2016^{5,6}$. Lymphoidneoplasms are classified as:

- Mature B cell neoplasm (MBCN)

- Mature T and NK cell neoplasm (MTCN)

- Post-transplant lymph proliferative disorders

- Hodgkin's disease (HL)

- Histiocytic and dendritic cell neoplasm (HDN)

- Myeloproliferative neoplasms (MPN)

- Myelodysplastic/myeloproliferative neoplasms
- Myelodysplastic syndrome (MDS)

- Acute myeloid leukemia with related neoplasms (AML)

- Blastic plasmacytoid dendritic cell neoplasms

- Acute leukemia with ambiguous lineage

- B and T lymphoblastic lymphoma/ leukemia (ALL) ${ }^{\mathbf{5 , 6}}$.

\section{Methods}

For this cross-sectional study, data have been collected from the department of oncology. Hematological malignancies were analyzed clinically and with laboratory parameters. patients diagnosed as leukemia, myeloproliferative neoplasm and myelodysplastic syndrome were initially analyzed with complete blood counts and peripheral smear and diagnosed on the basis of immune phenotyping and cytogenetic and molecular markers in some cases. After clinical examination lymphomas were diagnosed on the basis of histopathology and Immunohistochemistry of Excised lymph node. Plasma cell dyscrasias were assessed clinically for features of CRAB hypercalcemia, renal impairment, anemia, and lytic lesion. Evaluation was done by hemogram, biochemical parameters, and skeletal survey. Later plasma cell dyscrasia was diagnosed on the basis of bone marrow study, immunofixation electrophoresis, serum-free light chain assay, serum protein electrophoresis and myeloma defining events. 
Results

Table 1 Frequency and Distribution pattern of age (years) and sex in Lymphoid Neoplasm

\begin{tabular}{|c|c|c|c|c|c|c|c|c|}
\hline $\mathbf{L N}$ & $\begin{array}{c}1100(100 \\
\%)\end{array}$ & $\begin{array}{c}18-20 \\
\text { yrs. }\end{array}$ & 21-40yrs. & 41-60yrs. & $>60$ yrs. & Male & Female & M:F \\
\hline A. Lymphoid Neoplasm & $660(60 \%)$ & $10(0.9 \%)$ & $\begin{array}{c}180(14.5 \\
\%)\end{array}$ & $\begin{array}{c}360(32.75 \\
\%)\end{array}$ & $\begin{array}{c}130(11.9 \\
\%)\end{array}$ & $\begin{array}{c}500(45.5 \\
\%)\end{array}$ & $\begin{array}{c}160(14.5 \\
\%)\end{array}$ & $2.7: 1$ \\
\hline 1.Precuorsor Lymphoid & $80(7.27 \%)$ & $10(0.9 \%)$ & $40(3.6 \%)$ & $30(2.7 \%)$ & - & $70(6.36 \%)$ & $10(0.9 \%)$ & $7: 1$ \\
\hline a. B-ALL & $40(3.6 \%)$ & - & $30(2.7 \%)$ & $10(0.9 \%)$ & - & $40(3.6 \%)$ & - & - \\
\hline b. T-ALL & $40(3.6 \%)$ & $10(0.9 \%)$ & $10(0.9 \%)$ & $20(1.8 \%)$ & - & $30(2.7 \%)$ & $10(0.9 \%)$ & $3: 1$ \\
\hline 2.MBCN & $\begin{array}{c}480(43.6 \\
\%)\end{array}$ & - & $30(2.8 \%)$ & $320(29 \%)$ & $\begin{array}{c}130(11.9 \\
\%)\end{array}$ & $\begin{array}{c}360(32.7 \\
\%)\end{array}$ & $\begin{array}{c}120(10.9 \\
\%)\end{array}$ & $3: 1$ \\
\hline a. NHL & $120(10.9 \%)$ & - & $30(2.7 \%)$ & $40(3.6 \%)$ & $50(4.5 \%)$ & $80(7.27 \%)$ & $40(3.6 \%)$ & $2: 1$ \\
\hline a1. FL & $20(1.8 \%)$ & - & - & $20(1.8 \%)$ & - & $10(0.9 \%)$ & $10(0.9 \%)$ & $1: 1$ \\
\hline a2. MZL & $10(0.9 \%)$ & - & - & - & $10(0.9 \%)$ & $10(0.9 \%)$ & - & - \\
\hline a3. DLBCL & $60(5.5 \%)$ & - & $30(2.7 \%)$ & $20(1.8 \%)$ & $10(0.9 \%)$ & $40(3.6 \%)$ & $20(1.8 \%)$ & $2: 1$ \\
\hline a4. PMBCL & $10(0.9 \%)$ & - & - & - & $10(0.9 \%)$ & - & $10(0.9 \%)$ & - \\
\hline a5. PEL & $10(0.9 \%)$ & - & - & - & $10(0.9 \%)$ & $10(0.9 \%)$ & - & - \\
\hline a6. MCL & $10(0.9 \%)$ & - & - & - & $10(0.9 \%)$ & $10(0.9 \%)$ & - & - \\
\hline b. LPL & $10(0.9 \%)$ & - & - & $10(0.9 \%)$ & - & - & $10(0.9 \%)$ & - \\
\hline c. CLL & $30(2.7 \%)$ & - & - & $10(0.9 \%)$ & $20(1.8 \%)$ & $20(1.8 \%)$ & $10(0.9 \%)$ & $2: 1$ \\
\hline d. PCN & $320(29 \%)$ & - & - & $260(23.6 \%)$ & $60(5.5 \%)$ & $\begin{array}{c}260(23.6 \\
\%)\end{array}$ & $60(5.5 \%)$ & $4.3: 1$ \\
\hline 3.MTCN (NHL) & $40(3.6 \%)$ & & $40(3.6 \%)$ & & & $30(2.7 \%)$ & $10(0.9 \%)$ & $3: 1$ \\
\hline a. PCALCL & $10(0.9 \%)$ & - & $10(0.9 \%)$ & - & - & $10(0.9 \%)$ & - & - \\
\hline b. HSTCL & $10(0.9 \%)$ & - & $10(0.9 \%)$ & - & - & $10(0.9 \%)$ & - & - \\
\hline c. PTCL, NOS & $10(0.9 \%)$ & - & $10(0.9 \%)$ & - & - & $10(0.9 \%)$ & - & - \\
\hline \multirow[t]{2}{*}{ d. ATCL } & $10(0.9 \%)$ & - & $10(0.9 \%)$ & - & - & - & $10(0.9 \%)-$ & - \\
\hline & & - & & - & - & & - & - \\
\hline 4. HL & $60(5.6 \%)$ & - & $50(4.5 \%)$ & $10(0.9 \%)$ & - & $40(3.6 \%)$ & $20(1.8 \%)$ & $2: 1$ \\
\hline
\end{tabular}

H.M. = Hematological Malignancies, L.N. = Lymphoid Neoplasm

In this study, we had 1100 cases of hematological neoplasm (HN) from September 2018 till October 2019. Lymphoid neoplasm was the commonest hematological malignancies with 660 cases of $60.0 \%$ followed by myeloid neoplasm of 440 cases $40 \%$. Overall median age at diagnosis for all hematological malignancies was 55 years of age. We have excluded patient of less than 18 years of age. In this study, we found lymphoid neoplasm included MBCN 43.6\%, ALL (B \& T) 7.2\%, HL $5.6 \%$ and MTCN $3.6 \%$ plasma cell neoplasm (PCN) $29 \%$ was the commonest lymphoid neoplasm followed respectively by non-hodgkin lymphoma (NHL) 10.9\%, chronic lymphocytic leukemia (CLL) $2.7 \%$ and lymphoplasmacytic lymphoma (LPL) $0.9 \%$. NHL includes diffuse large B cell lymphoma (DLBCL) $5.5 \%$, follicular lymphoma (FL)1.8\%, mantle cell lymphoma (MCL) $0.9 \%$, marzinal zone lymphoma (MZL) $0.9 \%$, primary effusion lymphoma (PEL) $0.9 \%$, primary mediastinal $\mathrm{B}$ cell lymphoma (PMBCL)0.9\%, primary cutaneous anaplastic large Cell lymphoma (PCALCL) $0.9 \%$, hepatosplenic T cell lymphoma (HSTCL) 0.9\%, peripheral $\mathrm{T}$ cell lymphoma (PTCL) $0.9 \%$ and adult $\mathrm{T}$ cell lymphoma (ATCL)0.9\%. (Table 1). 
Gender Wise Distribution of Lymphoid Neoplasm Types Patients

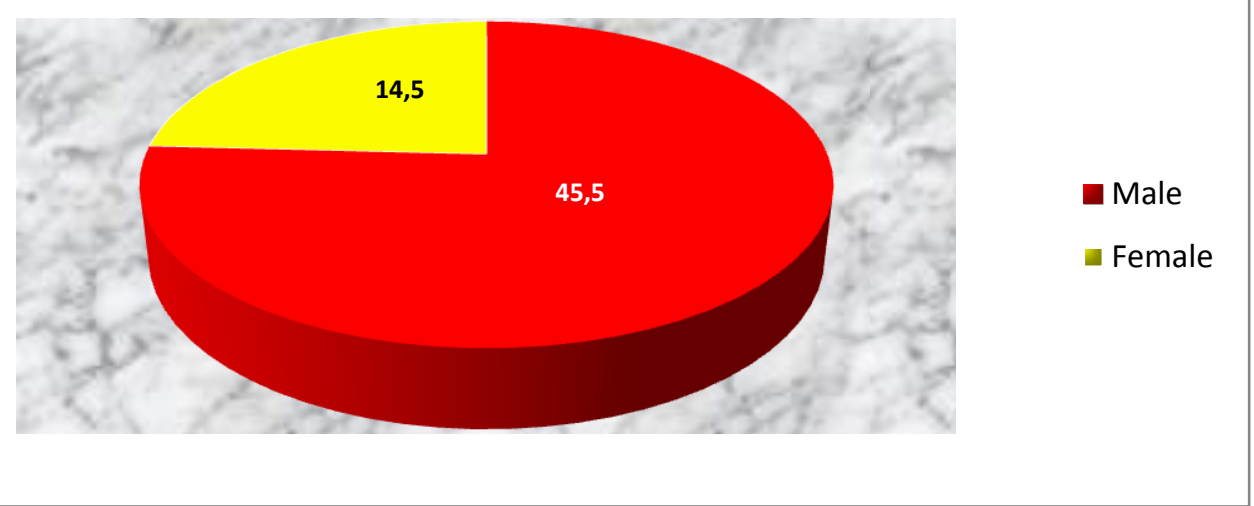

Figure-1: Gender wise Distribution of Lymphoid Neoplasm Types Patients

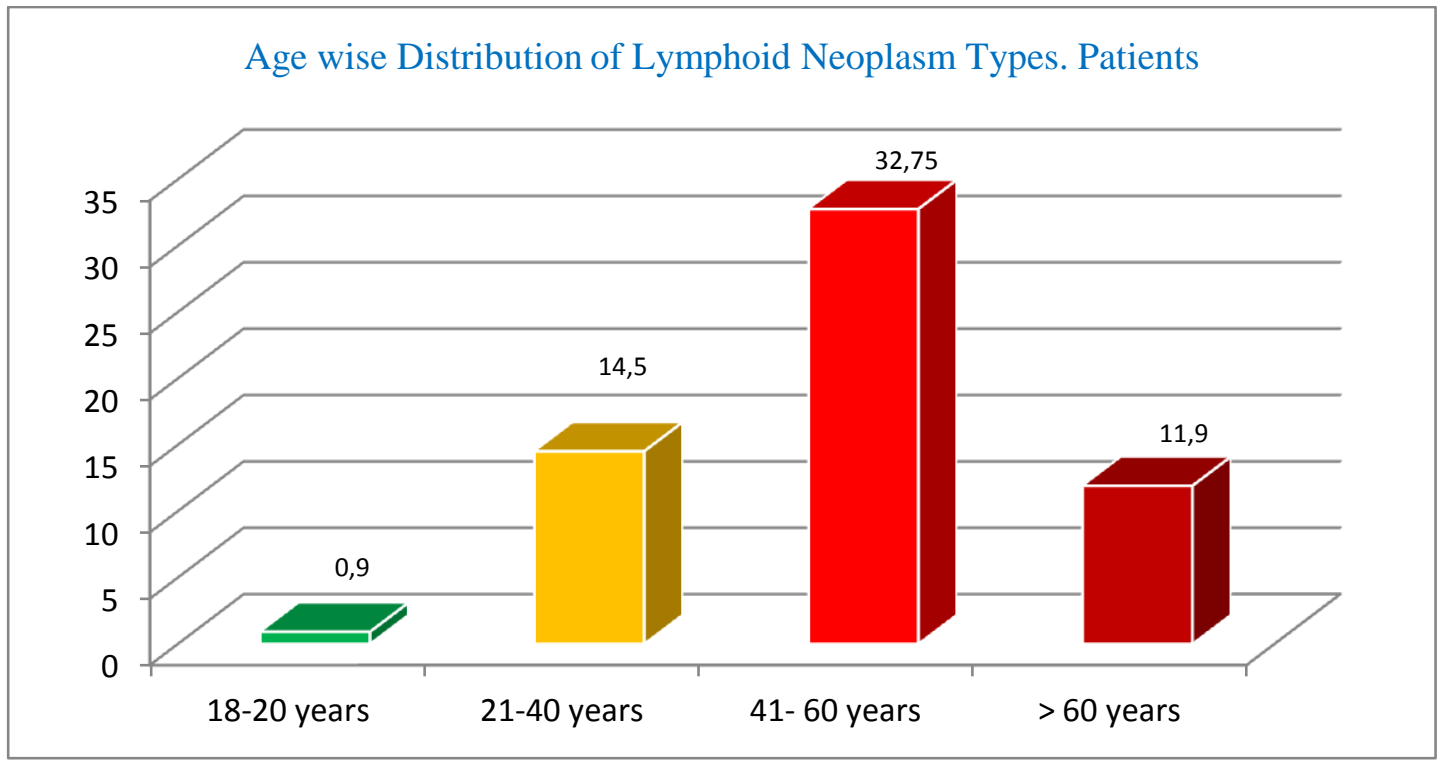

Figure-2: Age wise Distribution of Lymphoid Neoplasm Types Patients

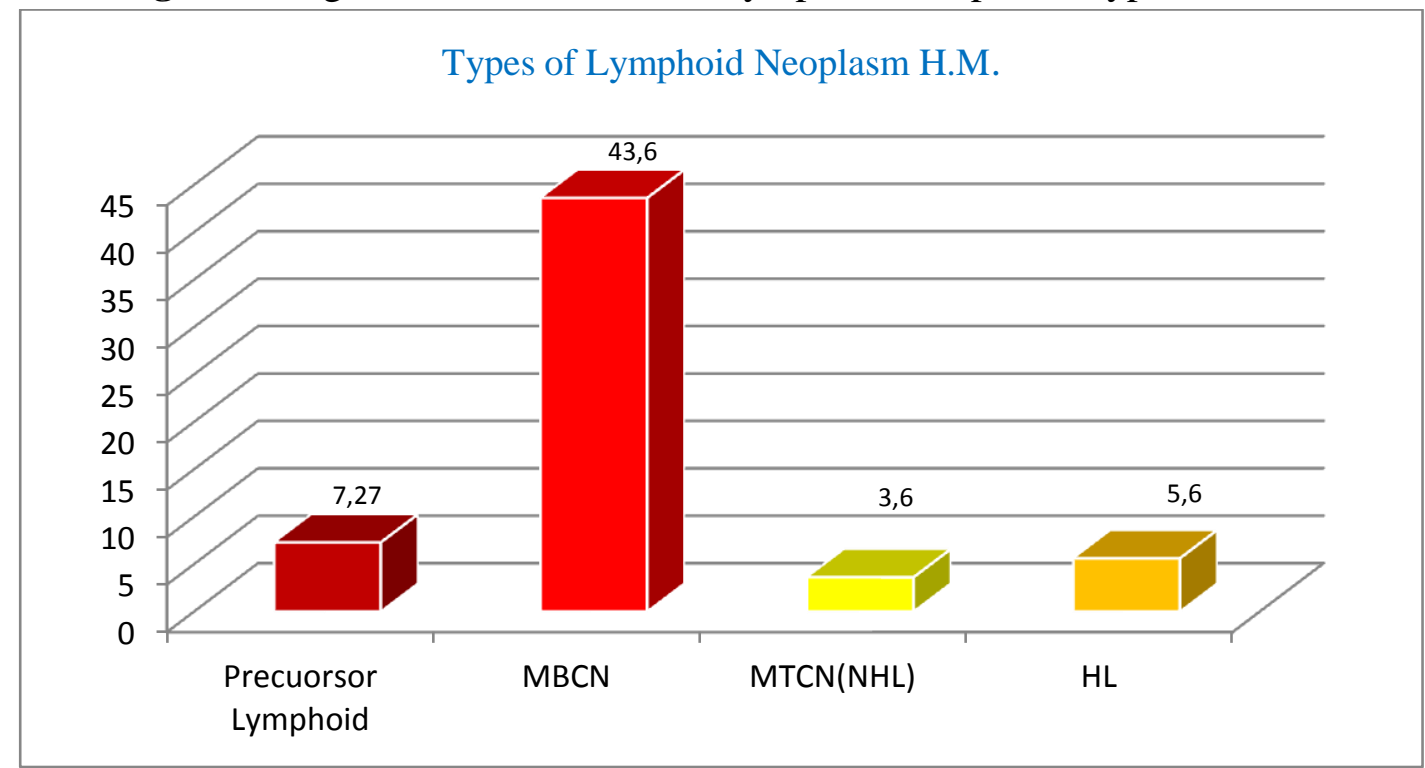

Figure-3: Types of Lymphoid Neoplasm H.M.

$\mathrm{MBCN}=$ Mature B cell neoplasms, MTCN/NHL= Mature Tcell neoplasms/Non-Hodgkin Lymphoma, $\mathrm{HL}=$ Hodgkin Lymphoma 
Table 2 Frequency and Distribution pattern of age (years) and gender in Myeloid Neoplasm

\begin{tabular}{|l|c|c|c|c|c|c|c|}
\hline MN & $\mathbf{1 1 0 0}(\mathbf{1 0 0} \%)$ & $\mathbf{2 1 - 4 0 y r s .}$ & $\mathbf{4 1 - 6 0 y r s .}$ & $\mathbf{> 6 0}$ years & Male & Female & M:F \\
\hline $\begin{array}{l}\text { A.Myeloid } \\
\text { Neoplasm }\end{array}$ & $440(40 \%)$ & $107(9.7 \%)$ & $256(23.3 \%)$ & $77(7.0 \%)$ & $300(27.25 \%)$ & $140(12.75 \%)$ & $2.15: 1$ \\
\hline 1. AML & $178(16.2 \%)$ & $53(4.85 \%)$ & $79(7.22 \%)$ & $43(3.92 \%)$ & $136(12.40 \%)$ & $42(3.6 \%)$ & $3.25: 1$ \\
\hline 2. MPN & $229(20.8 \%)$ & $54(4.87 \%)$ & $142(13.05 \%)$ & $34(3.05 \%)$ & $152(13.84 \%)$ & $77(5.5 \%)$ & $1.98: 1$ \\
\hline a. CML & $135(12.25 \%)$ & $54(4.9 \%)$ & $58(5.46 \%)$ & $22(1.99 \%)$ & $80(7.27 \%)$ & $55(4.5 \%)$ & $1.45: 1$ \\
\hline b. PV & $25(2.25 \%)$ & - & $25(2.35 \%)$ & - & $25(2.25 \%)$ & - & - \\
\hline c. ET & $44(4.05 \%)$ & - & $34(2.90 \%)$ & $10(0.9 \%)$ & $30(2.7 \%)$ & $14(0.9 \%)$ & $2.15: 1$ \\
\hline d. PM & $25(2.25 \%)$ & - & $25(2.35 \%)$ & - & $25(2.25 \%)$ & - & - \\
\hline 3. MDS & $33(3.0 \%)$ & - & $33(3.0 \%)$ & - & $11(1.0 \%)$ & $22(2.0 \%)$ & $1: 2$ \\
\hline a. RCUD & $11(1.0 \%)$ & - & $11(1.0 \%)$ & - & $11(1.0 \%)$ & - & - \\
\hline b. RCMD & $11(1.0 \%)$ & - & $11(1.0 \%)$ & & - & $11(1.0 \%)$ & - \\
\hline c. RAEB & $11(1.0 \%)$ & - & $11(1.0 \%)$ & - & - & $11(1.0 \%)$ & - \\
\hline
\end{tabular}

H.M. = Hematological Malignancies, M.N. = Myeloid Neoplasm

Among the myeloid neoplasm (MN), myeloproliferative neoplasm (MPN) accounted for the maximum number of $20.8 \%$ followed by acute myeloid leukemia and precursor neoplasm (AML) of $16.2 \%$ then myelodysplastic syndromes (MDS) 3.0\%. In this study, out of 229 MPN cases, chronic myeloid leukemia (CML) were maximum number of cases accounting for $12.25 \%$ cases followed by essential thrombocythaemia(ET) $4.05 \%$, polycythemia vera (PV) $2.25 \%$ and primary myelofibrosis (PM) $2.25 \%$. Among MDS, refractory cytopenia with unilineage dysplasia (RCUD), refractory cytopenia with multilineage dysplasia (RCMD) and refractory anemia with excess blast (RAEB) all were equal number of cases that is $1.0 \%$. (Table 2)

In patient group of 21 to 40 years of age, NHL was the most common HM with $2.7 \%$ in lymphoid neoplasm and myeloid neoplasm, MPN were $4.87 \%$, AML $4.85 \%$ and B ALL $2.7 \%$ and T ALL $0.9 \%$. On the other hand, HL $4.5 \%$, CLL $0.9 \%$ and LPL $0.9 \%$ in age group 41 to 60 years. In MPN of the same group 41-60 years, CML5.46\%, ET 2.90\%, PV 2.35\%, PM $2.35 \%$ was the most common HM followed respectively by $\mathrm{PCN}$ accounting $23.6 \%$. In older patients of more than 61 years of age, PCN was the most common HM accounting 5.5\% followed by NHL 4.5\%, AML 3.92\%, CLL 1.8\%, MPN 3.05\%, CML $1.99 \%$ and ET $0.9 \%$. In myeloid neoplasm male accounted for $27.25 \%$ and female were $12.75 \%$ with male female ratio $2.15: 1$. In both sex, in males, lymphoid neoplasm was most frequent $\mathrm{HM}$ with $45.5 \%$ followed by female $14.5 \%$ with male female ratio 2.7:1. However, as a very rare and slow moving $\mathrm{MBCN}$ of $\mathrm{HM}$ among older age, lymphoplasmacytic lymphoma (LPL) was not seen in male group in this study.

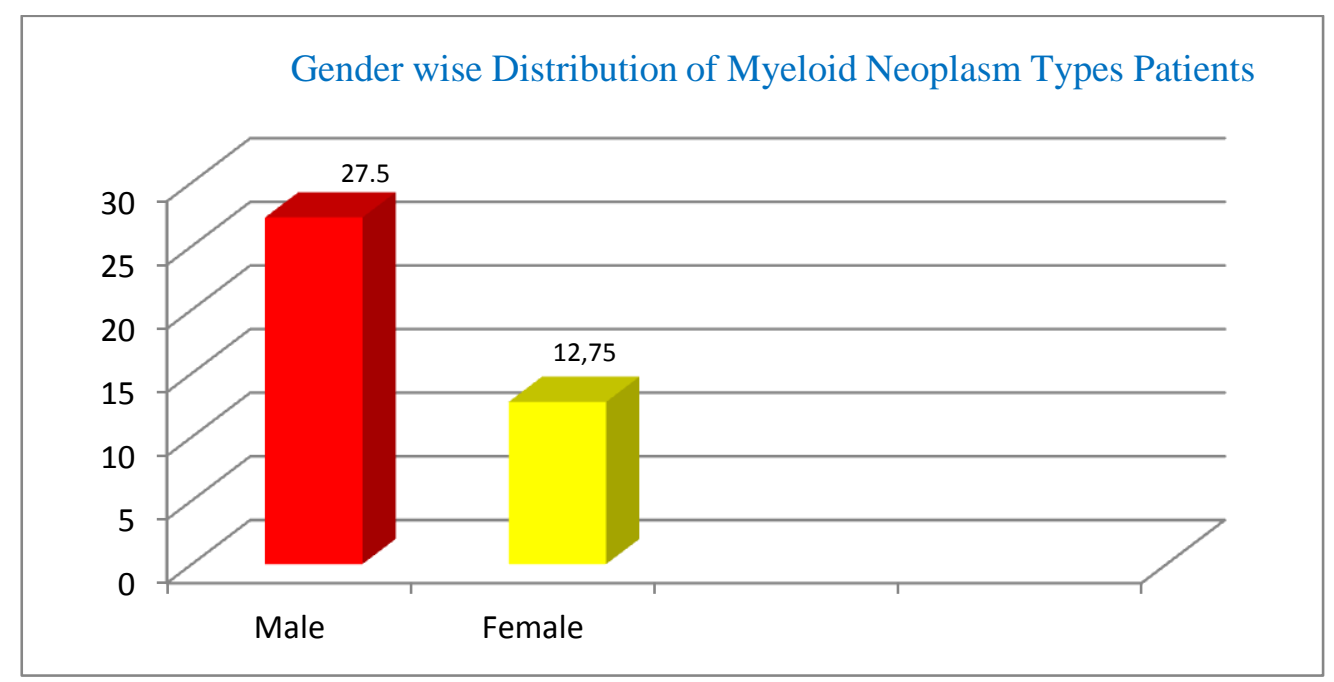

Figure-4: Gender wise Distribution of Myeloid Neoplasm Types Patients 


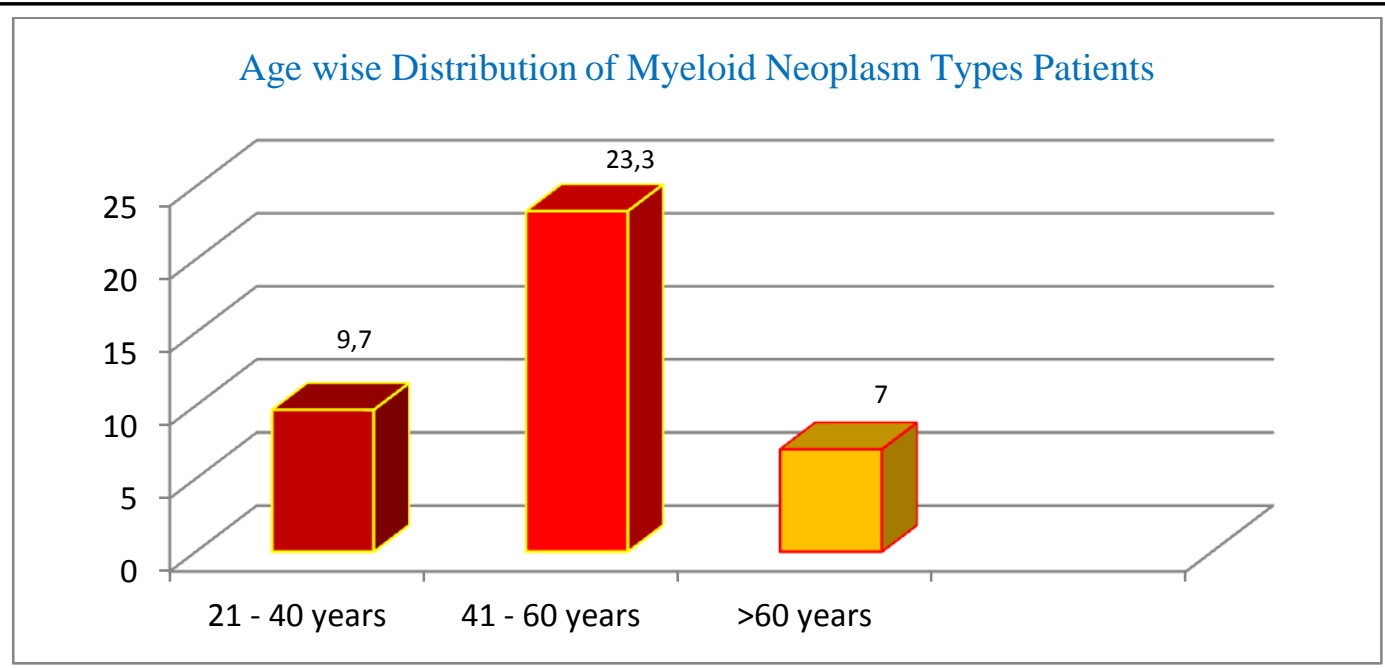

Figure-5: Age wise Distribution of Myeloid Neoplasm Types Patients

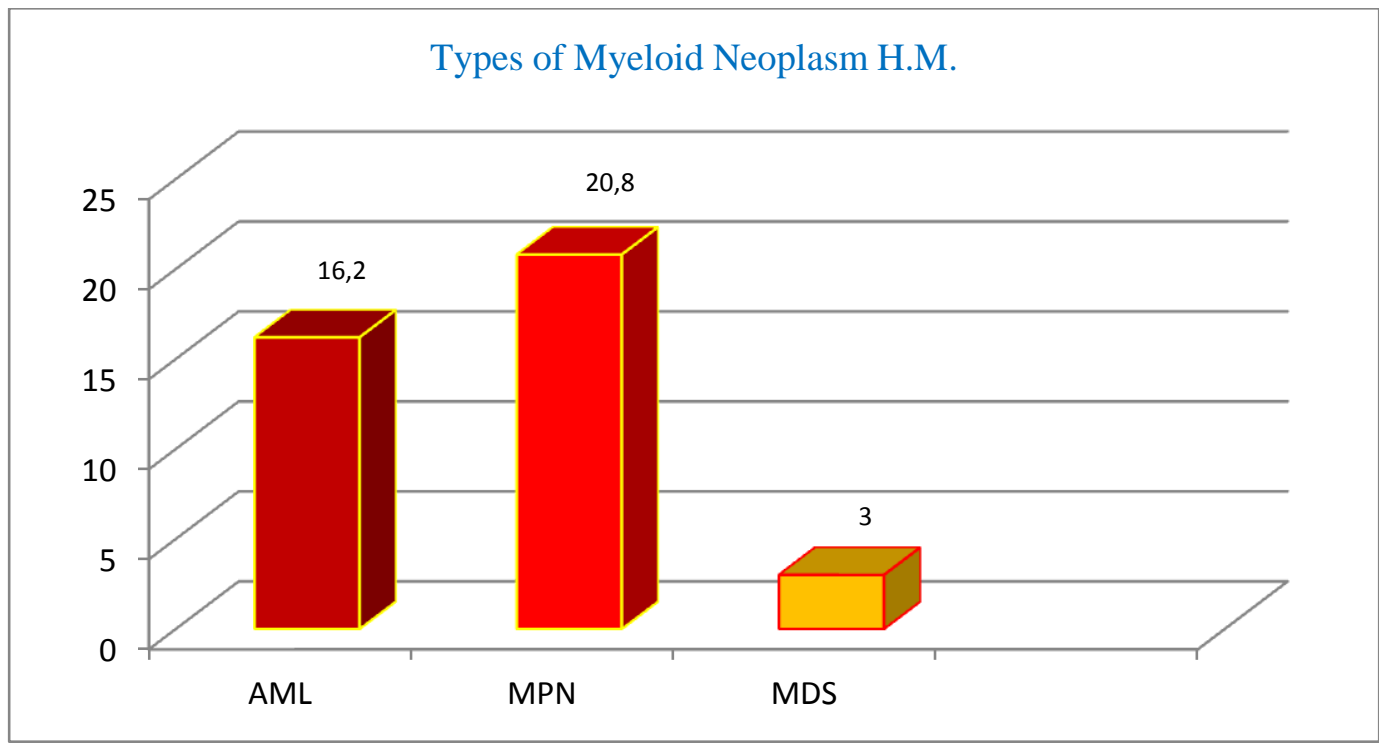

Figure-6: Types of Myeloid Neoplasm H.M.

$\mathrm{AML}=$ Acute Myeloid Leukemia, MPN= Myeloproliferative Neoplasms, MDS $=$ Hodgkin Lymphoma

\section{Discussion}

The study had shown the relative frequencies and distribution of several subtypes of hematological malignancies in different age groups and sex. The study done in Eastern Morocco, Bangladesh and Pakistan showed male predominance in hematological malignancies ${ }^{7,8,16}$. It has been known that most myeloid and lymphoid are more common in males than females with a justification for this being that men are more likely to be exposed to potentially carcinogenic occupational and environmental agents ${ }^{\mathbf{1 5}}$.I $\mathrm{n}$ both sex Lymphoid Neoplasm was most frequent HM followed by Myeloid Neoplasm and Histiocytic Neoplasm respectively. Here, the lymphoid neoplasm was the commonest hematological malignancy with $60.0 \%$ followed by myeloid neoplasm $40 \%$. The study was done in North America, Australia, Europe, and Africa, Eastern Morocco and Pakistan also revealed lymphoid Neoplasm is a frequent hematological malignancy ${ }^{9-13,16}$. Among the Myeloid neoplasms, MPN accounted for the maximum number of cases with $20.8 \%$ followed by AML $16.2 \%$ and MDS 3\%. The study done in Eastern Morocco had a similar result of MPN as the commonest myeloid neoplasm followed by AML and MDS ${ }^{7}$. The study done in Uttarakhand, India found AML was the commonest leukemia followed by $\mathrm{CML}^{\mathbf{1 4}}$. In our study, lymphoid neoplasm included $\mathrm{MBCN} 43.6 \%$, B \& T ALL 
were same $3.6 \%$, HL 5.6\% and MTCN 3.6\%. In this study, PCN (29\%) was the commonest lymphoid neoplasm followed respectively by NHL 10.9\%, CLL2.7\% and LPL 0.9\%. Among different subtypes of NHL diagnosed common was DLBCL 5.5\%. A study done in Eastern morocco showed NHL as the commonest lymphoid malignancy followed by HL. In that study DLBCL was the commonest $\mathrm{NHL}^{7}$.In Pakistan and the US, NHL is the commonest $\mathrm{HM}^{8}$. In males; lymphoid neoplasm was the most frequent $\mathrm{HM}$ with $45.5 \%$ followed by myeloid neoplasm of $27.25 \%$. MPN was the most frequent HM with $20.8 \%$ followed by AML 16.2\%, (CML $12.25 \%$, ET $4.05 \%$, PV $2.25 \%$, and PM $2.25 \%$ ). However, a review of hematological malignancies in eastern Morocco revealed slight variation in the frequency of different HM where NHL was the most frequent HM followed respectively by HL, PCN, MPN, CLL, AML, ALL, and finally MDS. ${ }^{7}$ PCN (Multiple myeloma) has been seen to affect males for frequently ${ }^{14}$. In female also, lymphoid neoplasm was most frequent $\mathrm{HM}$ with $14.5 \%$ followed by myeloid neoplasm of $12.75 \%$. NHL has been observed to be the most frequent HM followed by HL, PMN, LPL, AML, MDS, CLL and $A L L^{7}$.In females, there are slight similar results seen in these studies however there are different frequencies of HM in Male. In our study, patient under 20 years of age, T- ALL and LCH was seen each accounting for $0.9 \%$ of HM. However, HL has been seen to be the most common HM followed by NHL, AML, MPN, and $\mathrm{ALL}^{7}$. The study done in Eastern Morocco showed HL as the most frequent HM in this age group followed by respectively by NHL, MPN, AML, ALL and MM, CLL, MDS, and WM. In our study NHL was the most frequent HM whereas other study showed HL as the commonest $\mathrm{HM}^{7}$ In Bangladesh, AML has been commonly seen in this age group ${ }^{8}$.In adults aged 41 to 60 years, MPN 13.05\% (CML 5.46\%, ET 2.90\%, PV $2.35 \%$, and $\mathrm{PM} 2.35 \%$ ) was the most common HM. In this age group, another study showed NHL was predominant HM followed by MPN,
MM, HL, CLL, AML, MDS, ALL and $\mathrm{WM}^{7}$. In our study MPN and PCN was the commonest HM in this age group whereas other study showed NHL as the commonest HM. CLL, MDS, and PCN have been reported as common hematological malignancies in this age group ${ }^{8}$. Hematological malignancies arising from mature immunocompetent cells (mostly B lineage) predominate in adults $^{15}$. A variation in hematological malignancies with age suggests that the immune system rich in precursor cells in young people and predominance of germinal center and memory $\mathrm{B}$ cells in older adults ${ }^{15}$. In older patients of more than 61 years of age, AML was the most common HM accounting 3.92\% followed by MPN 3.05\%, CML 1.99\%. One of the studies showed NHL as the most common HM followed by MM, MPN, CLL, HL, MDS, AML, ALL and $\mathrm{WM}^{7}$. Our study shows MPN is the commonest HM whereas other studies showed NHL as the commonest HM. PCN (multiple myeloma) is more common in the older age groups with a median age of 61 years ${ }^{14}$.

\section{Conclusion}

Hematological malignancies can occur at any age group and men are more commonly affected. Lymphoid neoplasm is the most frequent HM. NHL is the most common HM in young adults whereas AML is the most common HM in the elderly. Hematological malignancies arising from Precursors T and B cells are common in children and adolescents whereas lymphoid neoplasms arising from the germinal center and memory $\mathrm{B}$ cells are common in adults.

\section{References}

1. John B(2004) Cousar Hematopoeitic lymphoid Neoplasms: principles of diagnosis-In Greer JP, Rodgers GM, Foerster J, Paraskevas F, Lukens JN, Glader B, editors Wintrobe's Clinical Hematology. Vol2 11th ed. Philadelphia USA: Lipincott Williams \& Wilkins, 1914 
2. Rowers CR Glover R lonial S, Brawely OW. Racial differences in the incidence and outcomes for patients with Hematological malignancies. Currprobl Cancer. 2007,31(3).182-201

3. Jaffe ES, Harris NL, Sten H, Vardiman JW. Pathology and genetics of tumors of hematopoietic and lymphoid tissues. World Health Organisation Classification of tumors. Lyon, France: larc Presse: 2001.

4. Vadiman JW, Harris NL, Brunning RD. The World Health Organisation (WHO) classification of myeloid neoplasms. Blood. 2002; 100(7)2292-302. https://doi. org/10.1182/blood-2002-04-

1199;PMid:12239137.

5. Daniel A. Arber, Attilio Orazi, Robert Hasserijian. The Upadated WHO Classification of Hematological Malignancies. The 2016 revision to the WHO Health Organization classification of myeloid neoplasms and acute leukemia. Blodd.2016; vol 127, nov 20. 2391- 2405

6. Steven H. Swerdlow, Elias Campo, Stefano A. The updated WHO Classification of Hematological Malignancies. The 2016 revision of world Health Organization classification of Lymphoid Neoplasms. Blood.2016; vol 127,nov 20. 2375-2390.

7. Mounia Elidrissi Errahhai, Manai Eldrissi, Redouane Boulouiz. Distribution and features of hematological malignancies in Eastern Morocco: a retrospective multicentre study over 5 years. BMC Cancer (2016) 16:159. https://doi.org/10.1186/s12885-016-22055 PMid:26915519 PMCid:PMC4768409

8. Hossain MS, Iqbal MS, Khan MA, Rabbani MG, KhatunH. Diagnosed Hematological malignancies in Bangladesh- a retrospective analysis of over 5000 cases from 10 specialised hospitals. BMC cancer.2014;14(1):438. https://doi.org/10.1186/1471- 2407-14438

PMid:24929433

PMCid:PMC4063230

9. Curado MP, Edwards B, Shin HR. Cancer Incidence in five continents, vol.9. International Agency for Research on Cancer;2007.

10. Sant M, Allemani C, Tereanu $\mathrm{C}$ et al. Incidence of hematologic malignancies in Europe by morphologic subtype; results of HAEACARE project. Blood.2010; 116(19):372-34.

https://doi.org/10.1182/blood-2010-05282632; PMid:20664057

11. Smith A, Howell D, Patmore R. Incidence haematological malignancy by subtype: a report from Haematological Malignancy Research Network. Br J Cancer.2011;105(11):1684-92 https://doi.org/10.1038/bjc.2011.450; PMid:22045184 PMCid:PMC3242607

12. Thiam D, Diop S, Diop $\mathrm{T}$ et al. Epidemiology and therapy of malignant hemopathies in Snega. Hematol Cell Ther. 1996;38(2):187-91. https://doi.org/10.1007/ s00282-9960187-5; PMid:8932001

13. Troussard X, Duchenet Vet al. Haematological malignancies incidence in Basse Normandie, France, for 19972004. Rev Epideiol Sante Publique. 2009;57(3):151-8.

https://doi.org/10.1016/j.respe.2009.02.20 4; PMid:19375876

14. Anuradha Kusum, Gita Negi, D Ushyant Singh Gaur, Sanjeev Kishore, Harsh Meena. Hematological Malignancies diagnosed by Bone marrow examination in a tertiary hospital at Uttarakhand, India. Indian J. Hematol. Blood Transfusions 24(1):7-11

15. A Smith, D howel, R Patmore, A Jack and $\mathrm{E}$ Roman. Incidence of haematological malignancy by subtype: a 
report from the Haematological Malignancy Research Network. British journal of Cancer (2011).105,1684-1692. https://doi.org/10.1038/ bjc.2011.450. PMid:22045184 PMCid:PMC3242607

16. Shahtaj Khan, Awal Mir, Baber Rehman Khattak, Shujaat Gull. Pattern of adulthood hematological malignancies in Khyber Pakhtunkhwa. J Blood Disord Transfus 2018, vol 9. 